\title{
Synthesis and in vitro kinetic study of novel mutual azo prodrug for inflammatory bowel disease
}

\author{
Yasser Fakri Mustafa \\ Department of Pharmaceutical Sciences, College of Pharmacy, \\ University of Mosul, Mosul, Iraq.
}

\begin{abstract}
Background: Inflammatory bowel disease (IBD) refers to idiopathic inflammatory diseases of the intestine, principally ulcerative colitis and Crohn's disease. IBD is characterized by chronic inflammation in the mucosal membrane of large intestine. 5ASA is the gold standard for the treatment of IBD and when searched for a better 5ASA prodrug, a novel mutual azo prodrug was designed and synthesized.

Methods: A mutual prodrug was synthesized by coupling $p$-phenetidine with salicylic acid. The stability of this prodrug in $\mathrm{HCl}$ buffer, in phosphate buffer and in rat fecal matter were monitored.

Results: The chemical structure of mutual prodrug was characterized by physical and spectroscopic techniques using FTIR, UV/Visible, ${ }^{1} \mathrm{H}-\mathrm{NMR}$ and ${ }^{13} \mathrm{C}-\mathrm{NMR}$ spectra. In vitro kinetic studies in $\mathrm{HCl}$ buffer ( $\mathrm{pH}$ 1.2) showed negligible release of 5-ASA and $p$-phenetidine, whereas in phosphate buffer $(\mathrm{pH} 7.4)$ only $(22.04 \%)$ release was observed over a period of ( $6 \mathrm{hr}$.). In rat fecal matter, the hydrolysis of mutual prodrug was almost complete $(77.96 \%$ ), with a half-life of $182.67 \mathrm{~min}$, following zero order kinetics.

Conclusion: The mutual prodrug was split in colon by the action of bacterial azoreductase into 5-ASA and $p$-phenetidine that constitute two anti-inflammatory compounds with different mechanisms of action. Therefore, this mutual prodrug is a promising colon specific prodrug for IBD and worthy of further study.
\end{abstract}

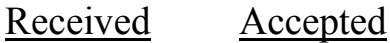

$\frac{\text { 2.9.2010 }}{30.11 .2011}$

Keywords: IBD, 5-ASA, p-phenetidine, azo coupling, mutual prodrug.

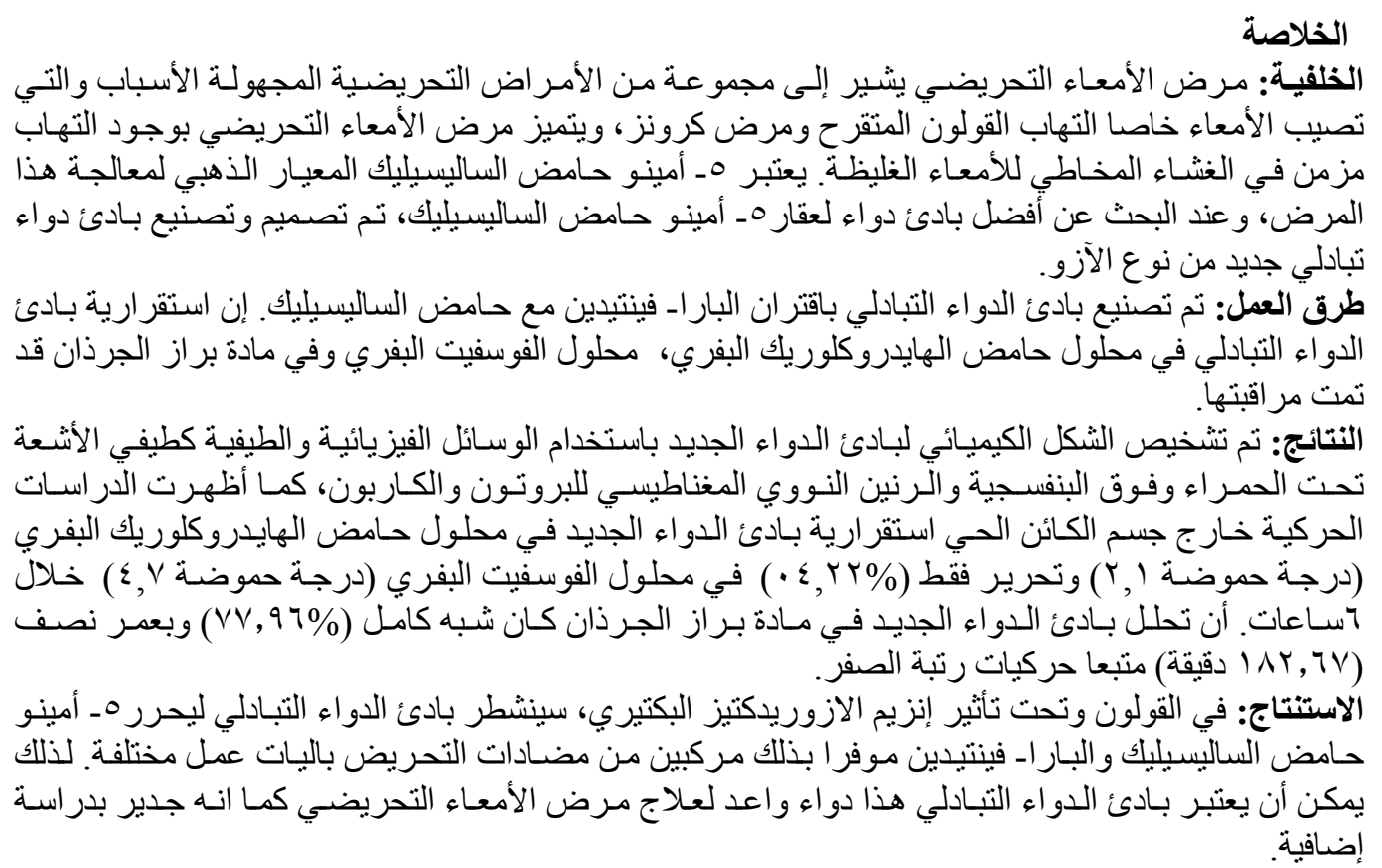


I nflammatory bowel disease (IBD) encompasses several chronic inflammatory conditions, most significantly ulcerative colitis and Crohn's disease ${ }^{1}$. IBD is characterized by chronic inflammation in the mucosal membrane of the small and/or large intestine ${ }^{2}$. The etiology of IBD remains unknown; however, two primary theories have been proffered focusing on either a specific persistent infectious agent ${ }^{3,4}$ or an abnormal host immune response to ubiquitous antigens in the luminal constituents. Evidence support the observation that patients with IBD are genetically susceptible to this disease and the defect targets are unable to effectively down-regulate the inflammatory response to specific antigens or luminal bacteria ${ }^{5}$. Although many treatments have been recommended for IBD, they do not treat the cause but are effective only in reducing the inflammation and accompanying symptoms in up to $80 \%$ of patients ${ }^{6}$.

Oral delivery is the most common and preferred route of drug administration, this is the ideal route to deliver compounds to colonic sites to treat IBD; however; the digestive tract exhibits several obstacles to drug delivery including gut motility, ${ }^{7}$ stomach intraluminal $\mathrm{pH}$ profiles ${ }^{8}$ and degradative enzymes ${ }^{9}$.

In order to achieve an effective colonic delivery, a drug needs to be protected from absorption and/or the environment of upper GI tract and then rapidly released into the proximal colon, which is the optimal site for colon-targeted delivery of the drug. Colonic drug delivery through colonspecific prodrug activation may be accomplished by the utilization of the high activity of certain enzymes at the target site relative to non-target tissues, enabling for prodrug conversion to active drug ${ }^{10}$.
The intestinal microflora consists of a coexisting mixture of aerobic, facultative anaerobic and strict anaerobic bacteria in a complex ecosystem. These bacteria produce a wide range of enzymes such as $\beta$ glucuronidase, $\beta$-xylosidase, $\quad \alpha$ arabinosidase, $\quad \beta$-galactosidase, nitroreductase, azoreductase, deaminase, urea hydroxylase, etc ${ }^{11,12}$.

5-Aminosalicylic acid (5-ASA) is an effective compound to attenuate the inflammatory response in IBD while its mechanism of action is not fully understood. Because 5-ASA usually fails to reach the colon leading to significant adverse effects, ${ }^{13}$ a prodrug approach for colonic delivery of 5ASA has become a rational system of drug delivery for the topical treatment of IBD $^{14}$.

5-ASA triggers the peroxisome proliferator-activated receptor (PPAR$\gamma$ ) family of nuclear receptors, which regulate inflammation, cell proliferation, apoptosis, and metabolic function. PPAR- $\gamma$ receptors are highly expressed in colonic epithelia and their expression is up-regulated by the gut bacteria $^{15}$.

Non-steroidal anti-inflammatory drugs (NSAIDs) are widely used in the treatment of chronic inflammatory states. In addition, they showed a promising activity for prevention and treatment of $\operatorname{IBD}^{16,17}$. When they are administered orally, a large amount of the NSAIDs are absorbed from the upper GIT and causes systemic side effects. Therefore, it is preferable to deliver the drug site-specifically to the colon. ${ }^{18}$

As amide or azo prodrugs, selective delivery of NSAIDs to colon can be useful in terms of reducing the administered dose and undesirable side-effects ${ }^{19,20}$ but the most important disadvantages of these prodrugs are the low bioavailability and the 
irritation cause by their carboxylic acid groups $^{21,22}$.

$P$-phenetidine is a minor metabolite of phenacetin and is a more potent inhibitor, even at a nanomolar level, of the prostaglandins synthesis than indomethacin, with greater selectivity to COX-2 inhibition ${ }^{23,24}$.

It was believed that $p$-phenetidine may cause renal toxicity and methemoglobinemia, but recently, researches confirm that the N-hydroxy metabolite which results from hepatic oxidation of $p$-phenetidine is responsible for these toxicities ${ }^{25,26}$.

\section{Experimental}

Materials $P$-phenetidine was synthesized in laboratory according to Williamson synthesis of ether ${ }^{27,28}$ via condensation of sodium $P$ aminophenoxide and ethyl chloride. All other chemicals were of analytical reagent grade and those of synthetic grade were purified prior to use.

\section{Instruments}

Thin layer chromatography (TLC) of the synthesized compound was performed on precoated plates of silica gel 60 F 5 (Merck) using iodine vapor and UV light for visualization. The solvent mixture employed for TLC was composed from chloroform: acetone (4:1).

Melting point of the product was determined by open capillary method on electrothermal CIA 9300 and is uncorrected.

Chemical structures were drawn by Chemdraw Office 2001 software. Ultraviolet spectrum of the synthesized compound was determined on Carrywinn U.V. Varian UV/Visible double-beam spectrophotometer in hydrochloric acid buffer ( $\mathrm{pH} 1.2)$, phosphate buffer ( $\mathrm{pH} 7.4$ ), chloroform and distilled water.

FTIR spectrum of the synthesized compound was recorded by Buck 500 scientific I.R. spectrophotometer in anhydrous potassium bromide (IR grade) pellet.

The ${ }^{1} \mathrm{H}-\mathrm{NMR}$ and ${ }^{13} \mathrm{C}$-NMR spectra of the synthesized compound were

recorded by Varian Mercury 400

MHz. (France)

Synthesis of azo prodrug ${ }^{29}$

A concentrated hydrochloric acid (16 ml) was added to a well stirred suspension of $p$-phenetidine citrate $(3.425 \mathrm{~g}, 0.025 \mathrm{~mol})$ in water $(12 \mathrm{ml})$ and the mixture was heated up to $70^{\circ} \mathrm{C}$ and maintained at that temperature till a clear solution obtained. After cooling the solution to $3^{\circ} \mathrm{C}$ in a cryostatic bath, a solution of sodium nitrite $(2 \mathrm{~g}, 0.028$ $\mathrm{mol})$ in water $(10 \mathrm{ml})$ was added dropwise over a period of 10 minutes with stirring. The reaction mixture was stirred at a temperature below $5^{\circ} \mathrm{C}$ for one hour. The excess of nitrous acid (tested by using moist starch iodide paper) was removed by adding required amount of sulphonic acid solution (10\%). The clear diazonium salt solution was obtained and used immediately in the coupling reaction.

Salicylic acid (3.45 g, $0.025 \mathrm{~mol})$ was dissolved in sodium hydroxide solution $(25 \mathrm{ml}, 10 \% \mathrm{w} / \mathrm{v})$. The solution was cooled to $3^{\circ} \mathrm{C}$ in cryostatic bath. To this well stirred solution, the above diazonium solution was added dropwise and the temperature kept below $5^{\circ} \mathrm{C}$. The reaction mass was further stirred for two hours at $5^{\circ} \mathrm{C}$ maintaining the $\mathrm{pH}$ 8.0 by adding required amount of $10 \%$ $\mathrm{w} / \mathrm{v}$ of sodium carbonate solution. The reaction mass was diluted with hot water $(80 \mathrm{ml})$ until the washings were neutral. Then diluted solution of $\mathrm{HCl}$ was added dropwise. The product was filtered off, dried and recrystallized from ethanol (scheme 1). 


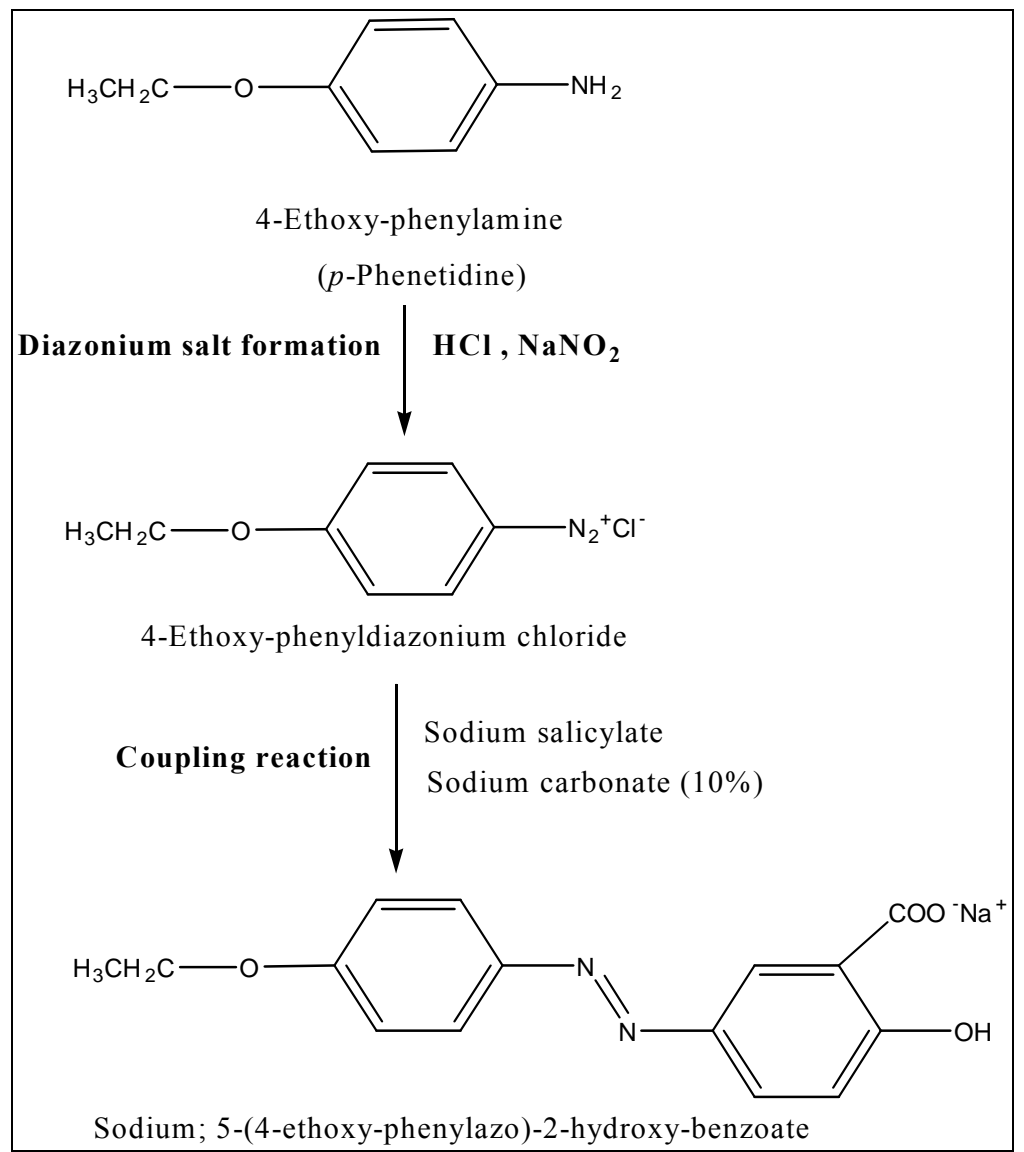

Scheme 1. Synthesis of azo prodrug

The purity of compound was established by TLC and its result showed that only a single spot was observed. The melting point was $217-$ $219^{\circ} \mathrm{C}$, the percentage of yield was $78 \%$ and the $R_{f}$ value was 0.43 .

\section{In vitro stability studies}

The stability of azo prodrug in $0.05 \mathrm{M}$ hydrochloric acid buffer ( $\mathrm{pH}$ 1.2) and in $0.05 \mathrm{M}$ phosphate buffer $(\mathrm{pH} 7.4)$ was monitored according to the following procedure ${ }^{30}$ :

A sample (10 mg, $0.035 \mathrm{mmol})$ of azo prodrug was introduced into a conical flask containing $900 \mathrm{ml}$ of $\mathrm{HCl}$ buffer; the resulting solution was kept at a constant temperature $\left(37 \pm 1^{\circ} \mathrm{C}\right)$ using a water bath with gentle stirring. When the UV spectra of 5-ASA, $p$ phenetidine and prodrug were overlaid, it was observed that the UV spectrum of prodrug did not interfere with the absorption ranges of 5-ASA and $p$-phenetidine, as is obvious from the difference in the $\lambda_{\max }$ values of 5 ASA (303 nm), p-phenetidine (247 $\mathrm{nm})$ and the prodrug $(385 \mathrm{~nm})$. Therefore the aliquots were directly estimated on UV/Visible spectrophotometer at $385 \mathrm{~nm}$ every 30 minutes for three hours to monitor the amount of prodrug remaining.

In order to examine the stability of azo prodrug in phosphate buffer, the same procedure as described above was followed, except that the phosphate buffer replaced the $\mathrm{HCl}$ buffer and the UV/Visible data were taken at $476 \mathrm{~nm}$ every 30 minutes for six hours. 
Table 1. Kinetic data obtained from the stability studies

\begin{tabular}{|l|c|c|c|c|}
\hline Type of buffer & A & $\lambda_{\max }(\mathrm{nm})$ & $\mathrm{a}(\mathrm{mmole})$ & $\varepsilon$ \\
\hline HCl buffer (pH 1.2) & 0.0413 & 385 & 0.035 & 589.75 \\
\hline Phosphate buffer (pH 7.4) & 0.0537 & 476 & 0.035 & 766.81 \\
\hline
\end{tabular}

$\mathrm{A}=$ absorbance, $\mathrm{a}=$ conc. of mutual prodrug at zero time and $\varepsilon=$ absorbance coefficient.

Release study in rat fecal matter ${ }^{31}$ The azo prodrug was dissolved in phosphate buffer ( $\mathrm{pH} 7.4$ ), so that the final concentration of the solution was $250 \mathrm{mg} / \mathrm{ml}$. Fresh fecal material of rats was weighed $(1 \mathrm{~g})$ and placed in set of test tubes. To each test tube, $(1 \mathrm{ml})$ of the prodrug solution was added and diluted to $(5 \mathrm{ml})$ with phosphate buffer to achieve a final concentration of 50 $\mathrm{mg} / \mathrm{ml}$. The test tubes were incubated at $37^{\circ} \mathrm{C}$.

Every (30 minutes) for six hours, one test tube was removed from a water bath and the concentration of azo prodrug was directly estimated on a double beam UV/Visible spectrophotometer at $476 \mathrm{~nm}$. All the kinetic studies were carried out in triplicate and monitored by the decrease in prodrug concentration with time.

\section{Results and Discussion}

Colonic drug delivery has gained a great importance not just for the delivery of drugs for the treatment of local diseases associated with colon like Crohn's disease and ulcerative colitis but also for the potential it holds for the systemic delivery of proteins and therapeutic peptides ${ }^{32}$. The large intestine, though difficult to reach by peroral delivery, is still deemed to be the ideal site for the delivery of agents to cure the local diseases of colon. ${ }^{33}$ The most critical challenge in such drug delivery approach is to preserve the formulation during its passage through the stomach and about first six meters of the small intestine ${ }^{34,35}$.

Targeted drug delivery to the colon would therefore, ensure direct treatment at the disease site and, consequently, lower the administered dose and systemic side effects. ${ }^{36} \mathrm{~A}$ variety of approaches have been developed for the purpose of achieving colonic targeting, one of the most common approaches is azo prodrugs ${ }^{37}$. This type of prodrugs is designed to undergo minimal absorption and hydrolysis in the upper GIT and undergo enzymatic hydrolysis via azoreductase to release the active drug moiety in colon ${ }^{38}$.

In treatment of IBD, 5-ASA usually coupled with a carrier for colon targeting, ${ }^{39}$ the most commonly used naturally occurring colontargeting carriers are polysaccharides such as cyclodextrins 40 and amino acids such as aspartic acid, glutamic acid, glycine, lysine and tyrosine, these carriers are not toxic but have no pharmacological activity ${ }^{41-43}$.

The potential of some NSAIDs as colon targeted delivery systems for treatment of IBD was studied, but these systems have several disadvantages such as low bioavailability and irritation caused by their carboxylic acid group ${ }^{44}$.

In this study, a novel mutual azo prodrug of 5-ASA with $p$-phenetidine was synthesized. The azo linkage of this mutual prodrug was proposed to be broken in colon by the action of azoreductase produced by colonic microflora to release two compounds with different anti-inflammatory mechanisms of action. This study proposed that this novel prodrug may be beneficial in treatment of IBD.

\section{Infrared spectrum of azo prodrug}

The infrared spectrum $(\mathrm{KBr})$ of azo prodrug showed a weak band at 1494 
$\mathrm{cm}^{-1}$ for unsymmetrical $p$-substituted azo group. The band at $3356 \mathrm{~cm}^{-1}$ indicating the presence of phenolic$\mathrm{OH}$ (H-bonded). The bands at 1612 $\mathrm{cm}^{-1}, 1085 \mathrm{~cm}^{-1}$ can be attributed to aromatic ether. The characteristic bands at $1754 \mathrm{~cm}^{-1}$ and at $2935 \mathrm{~cm}^{-1}$ are due to the stretching of carbonyl and hydroxyl groups of carboxylic acid while the bands appear at 3095 $\mathrm{cm}^{-1}, 2885 \mathrm{~cm}^{-1}$ are corresponding to the stretching of methylene and methyl groups respectively. The strong bands at $824 \mathrm{~cm}^{-1}, 805 \mathrm{~cm}^{-1}$ refer to the bending of $\mathrm{C}-\mathrm{H}$ of disubstituted and trisubstituted aromatic rings respectively.

UV/Visible spectrum of azo prodrug The ultraviolet spectrum of azo prodrug gave different $\lambda_{\max }$ values in different solvents such as: $\lambda_{\max }$ in an aqueous acidic solution $(\mathrm{pH} 1.2)=385$ $\mathrm{nm}, \lambda_{\max }$ in an aqueous phosphate buffer solution $(\mathrm{pH} \mathrm{7.4)}=476 \mathrm{~nm}$, $\lambda_{\max }$ in chloroform $=412 \mathrm{~nm}$ and the $\lambda_{\max }$ in distilled water $=454 \mathrm{~nm}$. The $\lambda_{\max }$ values of azo prodrug in different solvents showed an increasing in magnitude compared with 5-ASA, this red shift or bathochromic shift is due to the increase in conjugation indicating the formation of azo bond. $^{45,46}$

${ }^{1}$ H-NMR spectrum of azo prodrug ${ }^{1} \mathrm{H}-\mathrm{NMR}$ (DMSO-d ${ }_{6}$ ) spectrum of azo prodrug showed the chemical shifts for the protons of methyl and methylene groups at $\delta 1.91-2.07 \mathrm{ppm}(\mathrm{t}, 3 \mathrm{H})$ and at $\delta \quad 3.06-3.29 \quad \mathrm{ppm} \quad(\mathrm{q}, \quad 4 \mathrm{H})$ respectively. This spectrum clearly indicated the proton of phenolic-OH at $\delta 6.23 \mathrm{ppm}(\mathrm{s}, 1 \mathrm{H})$. The protons of aromatic rings resonated at $\delta$ 6.90-6.96 ppm $(\mathrm{m}, 3 \mathrm{H})$ and at $\delta 7.13-7.34 \mathrm{ppm}$ (dd, 4H) while the proton of carboxylic acid group resonated at $\delta$ 11.14 ppm (s, 1H).

${ }^{13}$ C-NMR spectrum of azo prodrug

${ }^{13} \mathrm{C}-\mathrm{NMR}$ spectrum of azo prodrug reported that the carbons of methyl and methylene groups resonated at $\delta$ $14.72 \mathrm{ppm}$ and at $\delta 67.94 \mathrm{ppm}$ respectively. The carbon of aromatic ring attached to $\mathrm{COOH}$ resonated at $\delta$ $129.48 \mathrm{ppm}$ while the carbon atoms of aromatic rings attached to azo bond resonated at $\delta 132.94 \mathrm{ppm}$ and at $\delta$ $134.61 \mathrm{ppm}$ which confirmed the formation of azo bond.

The carbon atom of aromatic ring attached to $\mathrm{OH}$ resonated at $\delta 153.45$ ppm while the carbon atom of aromatic ring attached to ether group resonated at $\delta 164.12 \mathrm{ppm}$. This spectrum clearly indicated that the carbon atom of $(\mathrm{C}=\mathrm{O})$ group resonated at $\delta 170.71 \mathrm{ppm}$.

\section{In vitro kinetic studies}

The azo prodrug in $(0.05 \mathrm{M})$ hydrochloric acid buffer $(\mathrm{pH}$ 1.2) showed negligible release of 5-ASA and $p$-phenetidine. Whereas in phosphate buffer (pH 7.4), only (22.04 $\%$ ) release was observed over a period of six hours. The objective of bypassing the upper gastrointestinal tract with minimum prodrug release was achieved. Further study in rat fecal matter was carried out to confirm the colonic reduction of azo prodrug over a period of six hours; azo prodrug gave $(77.96 \%)$ cumulative release of 5-ASA and $p$-phenetidine.

Table 2 shows the kinetic data obtained from the release study of azo prodrug in rat fecal matter at $37^{\circ} \mathrm{C}$ and $\lambda_{\text {max }}(476 \mathrm{~nm})$. 
Table 2. Kinetic data of the release study in rat fecal matter

\begin{tabular}{|c|c|c|c|c|}
\hline Absorbance & $\begin{array}{l}\text { Time } \\
(\mathrm{min} .)\end{array}$ & $\begin{array}{c}(\mathrm{a}-\mathrm{x}) \\
\left(\mathrm{mol} \times 10^{6}\right)\end{array}$ & $\begin{array}{c}\mathrm{x} \\
\left(\mathrm{mol} \times 10^{6}\right)\end{array}$ & $\begin{array}{l}\text { Cumulated } \\
\text { drug release } \\
(\%)\end{array}$ \\
\hline 0.0537 & 0 & 35 & 0 & 0 \\
\hline 0.0492 & 30 & 32.05 & 2.95 & 8.43 \\
\hline 0.0458 & 60 & 29.88 & 5.12 & 14.63 \\
\hline 0.0397 & 90 & 25.91 & 9.09 & 25.97 \\
\hline 0.0355 & 120 & 23.18 & 11.82 & 33.77 \\
\hline 0.0307 & 150 & 20.05 & 14.95 & 42.71 \\
\hline 0.0267 & 180 & 17.43 & 17.57 & 50.20 \\
\hline 0.0224 & 210 & 14.59 & 20.41 & 58.31 \\
\hline 0.0180 & 240 & 11.73 & 23.27 & 66.49 \\
\hline 0.0132 & 270 & 8.58 & 26.42 & 75.49 \\
\hline 0.0093 & 300 & 6.09 & 28.91 & 82.60 \\
\hline 0.0036 & 330 & 2.38 & 32.62 & 93.20 \\
\hline 0 & 360 & 0 & 35 & 100 \\
\hline
\end{tabular}

$(\mathrm{a})=$ conc. of azo prodrug at time zero and equal to $\left(35 \times 10^{-6} \mathrm{~mole}\right),(\mathrm{a}-\mathrm{x})=$ conc. of azo prodrug remaining for any time.

The release study of azo produg in rat fecal matter followed zero order kinetics (Figures 1, 2), the $t_{1 / 2}$ (average of three trials) of azo prodrug was found to be (182.67 min), whereas the rate constant $(\mathrm{k})$ was found to be $\left(0.0958 \times 10^{-6} \pm 0.0001\right)$.

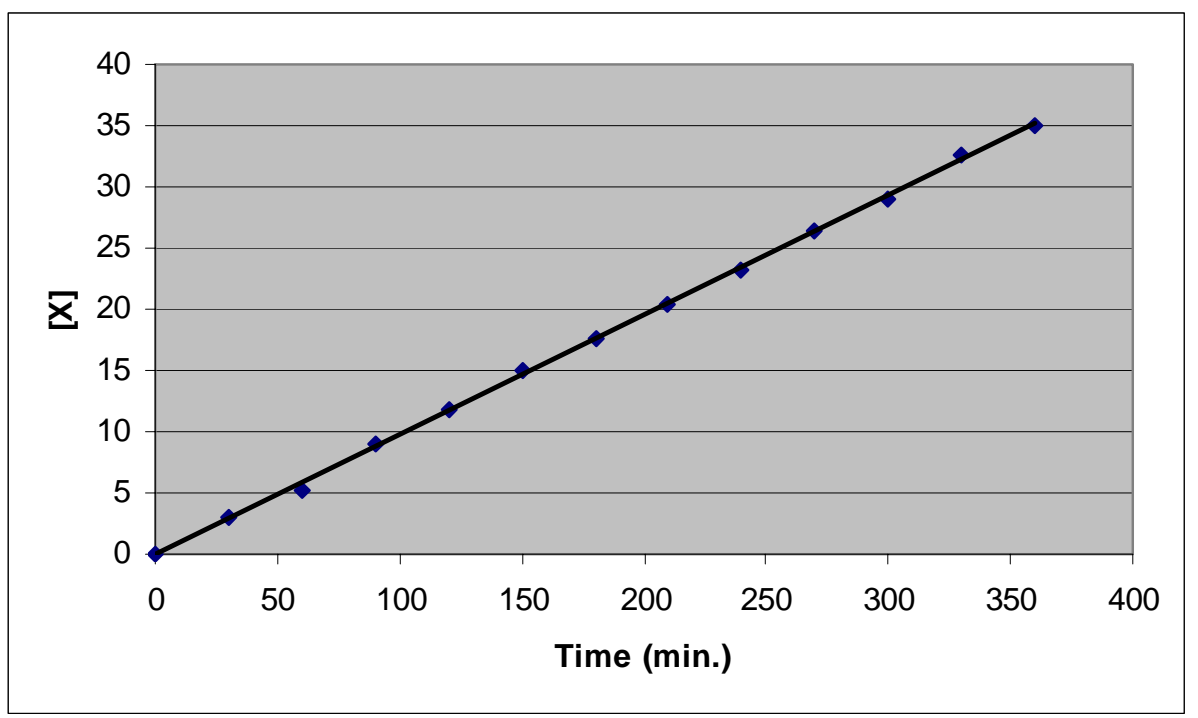

Figure 1. The slope for release study of the azo prodrug in rat fecal matter 


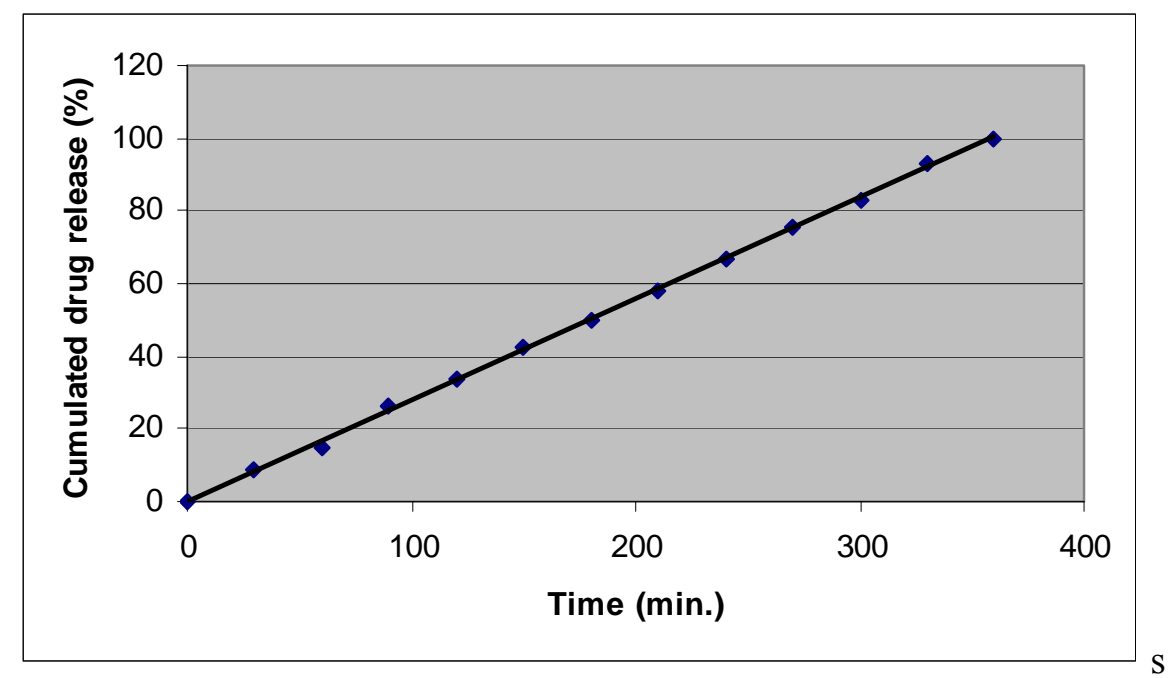

Figure 2. Release profile of 5-ASA and $p$-phenetidine from their azo prodrug in rat fecal matter.

\section{Conclusion}

In the present work, a novel mutual azo prodrug was synthesized by coupling $p$-phenetidine with salicylic acid and its chemical structure was characterized by physical and spectroscopic techniques, as FTIR, UV/Visible, ${ }^{1} \mathrm{H}-\mathrm{NMR}$ and ${ }^{13} \mathrm{C}-\mathrm{NMR}$ spectra. Properties of this prodrug acting as a colon-specific compound was evaluated depending on in vitro kinetic studies in $\mathrm{HCl}$ buffer, in phosphate buffer and in rat fecal matter. The results showed that only a small fraction of novel prodrug was hydrolyzed in upper gastrointestinal tract and the most fraction was delivered to the colon and split by bacterial azoreductase to liberate $p$ phenetidine and 5-ASA. Therefore, this prodrug is a promising colon specific prodrug for IBD and worthy of further study.

\section{Acknowledgment}

My deepest thank and gratitude to Prof. Faris Th. Abachi, Dr. Waffaa AlSheikh and Dr. Rana Putrus for helping me in this work.

\section{References}

1. Head KA, Jurenka JS. Inflammatory bowel disease Part
1: Ulcerative collitis pathophysiology, conventional and alternative treatment options. Altern Med Rev 2003;8:247-83.

2. Podolskiy DK. Inflammatory bowel disease. N Engl J Med 2002 ;347:417-29.

3. Helieh SO, Jeffrey L. Application of prodrugs to inflammatory diseases of the gut. Molecules 2008;13:452-74.

4. Robertson DJ, Sandler RS. Measles virus and Crohn's disease: a critical appraisal of the current literature. Inflamm Bowel Dis 2001;7:51-7.

5. Shanahan F. Inflammatory bowel disease: immunodiagnostics, immuno-therapeutics and ecotherapeutics. Gastroenterol 2001;120:622-35.

6. Cohen RD, Woseth DM, Thistel RA, Hanauer SB. A meta-analysis and overview literature on treatment options for left-sided ulcerative colitis and ulcerative proctitis. Am J Gastroenterol 2000;95:1263-76.

7. Tursi A, Brandimarte G, Giorgetti GM, Nasi G. Assessment of orocaecal transit time in different localization of Crohn's disease and 
its possible influence on clinical response to therapy. Eur J Gastroenterol Hepatol 2003;15:6974.

8. Schwab M, Klotz U. pharmacokinetic consideration in the treatment of inflammatory bowel disease. Clin Pharmacokinet 2001;40:723-51.

9. Dressman JB, Vetzoni M., Goumas K, Reppas C. Estimating drug solubility in the gastrointestinal tract. Adv Drug Deli Rev 2007;59:591-602.

10. Sands BE. Therapy of inflammatory bowel disease. Gastroenterology 2000;118:68-82.

11. Eckburg PB, Bernstein CN, Purdom E, Dethlefsen LM and Relman DA. Diversity of the human intestinal microflora. Science 2005;308:1635-8.

12. Sinha VR, Kumria R. Microbially triggered drug delivery to the colon. Eur J Pharm Sci 2003;18:318.

13. Stein RB, Hanauer SB. Comparative tolerability of treatments for inflammatory bowel disease. Drug Saf 2000;23:429-48.

14. Frieri G, Giacomelli RM, Pimpo G, Caprilli R. Mucosal 5aminosalicylic acid concentration inversely correlates with severity of colonic inflammation in patients with ulcerative colitis. Gut 2000;47:410-14.

15. Dubuquoy L, Rousseaux C, Thuru $\mathrm{X}$, Peyrin-Biroulet L, et al. $\mathrm{P}$. PPAR- $\gamma$ as a new therapeutic target in inflammatory bowel disease. Gut 2006;55:1341-9.

16. Myers C, Koki A, Pamukcu R, et al. Proapoptotic anti-inflammatory drugs. Urol 2001;57:73-6.

17. Yamazaki R, Kusunoki N, Matsuzaki T, et al. Selective cyclooxygenase-2 inhibitors show a differential ability to inhibit proliferation and induce apoptosis of colon adenocarcinoma cells. FEBS Lett 2002;53:278-84.

18. Jung YJ, Lee JS, Kim YM. Colonspecific prodrugs of 5aminosalicylic acid: synthesis and in vitro/invivo properties of acidic amino acid derivatives of 5aminosalicylic acid. J Pharm Sci 2001;90:1767-75.

19. Anil KP, Rajesh KD, Kamla PA. Optimizing delivery of flurbiprofen to the colon using a targeted prodrug approach. J Pharm Pharmacol 2008;60:607-13.

20. Raymond K, Jennie L, Mehdi B. NO-donating NSAIDS inhibit colon cancer cell growth more potently than traditional NSAIDs: a general pharmacological property. Biochem Pharm 2004;67:2197-2205.

21. Ibekwe VC, Kendall RA, Basit AW. Drug delivery to the colon. Adv. Drug Deliv Rev 2004;12:2730.

22. Jung B, Babier V, Brickner H, et al. Mechanisms of sulindacinduced apoptosis and cell cycle arrest. Cancer Lett 2005;219:1525.

23. Kankuri E, Solatunturi E, Vapaatalo H. Effects of phenacetin and its metabolite $p$-phenetidine on COX-1 and COX-2 activities. Thromb Res 2003;110:299-303.

24. Joachim B, Franz V, Gotthard W. Inhibition of prostaglandin synthetases derived from neural, glial cells of renal medulla by ortho-, meta- and para-substituted aminophenolic compounds. Prostag Leuk med 1983;10:31929.

25. Nelson SD, Traqer WF. The use of deuterium isotope effects to probe the active site properties, mechanism of cytochrome P-450 catalyzed reactions and mechanisms of metabolically 
dependent toxicity. Drug Metab Dispos 2003;31:1481-98.

26. Jensen CB, Jollow $\mathrm{Dj}$. The role of $\mathrm{N}$-hydroxyphenetidine in phenacetin-induced hemolytic anemia. Toxical Appl Pharmacol 1991;111:1-12.

27. Kini SG, Bhat AR, Bryant B, et al. Synthesis, antitubercular activity and docking study of new cyclic azole substituted diphenyl ether derivatives. Eur J Med Chem 2009;44: 492-500.

28. Kini SG, Bhat AR, Pan Z, et al. Synthesis and antitubercular activity of heterocyclic substituted diphenyl ether derivatives. J Enzyme Inhib Med Chem 2010;5:49-54.

29. Sanjay FT, Dinesh MP, Manish $\mathrm{PP}$, et al. Synthesis and antibacterial activity of new pyrazolo[3,4-b] quinoline based heterocyclic azo compounds and their dyeing performance. J Saudi Pharmaceut 2007;15:48-54.

30. Nagpal D, Singh R, Gairola N, et al. Mutual azo prodrug of 5aminosalicylic acid for colon targeted drug delivery: synthesis, kinetic studies and pharmacological evaluation. Indian J Pharma Sci 2006;68:171-8.

31. Dhaneshwar SS, Gairola N, Kandpal M, et al. Synthesis, kinetic studies and pharmacological evaluation of mutual azo prodrug of 5aminosalicylic acid with Dphenylalanine for colon specific delivery in inflammatory bowel disease. Bioorg Med Chem Lett 2007; 17:1897-1902.

32. Laila FA, Sajeev C. Multiparticular formulation: Approach to colon specific drug delivery. J Phar Pharmaceut Sci 2006;9:327-38.

33. Anekant J, Yashwant G, Sanjay KJ. Perspectives of biodegradable natural polysaccharides for sitespecific drug delivery to the colon. J Phar Pharmaceut. Sci 2007;10:86-128.

34. Sinha VR, Kumria R. Colonic drug delivery: prodrug approach. Pharmaceut Res 2001;18:557-64.

35. Guyvan DM. Colon drug delivery. Exp Opin Drug Del 2006;3:11125.

36. Yang L, Chu JS, Fix JA. Colonspecific drug delivery: new approaches and in vitro/in vivo evaluation. Int $\mathrm{J}$ Pharm 2002;235:1-15.

37. Gaurav T, Ruchi T, Pranay W, et al. Primary and new approaches for colon targeted drug delivery. Inter J Drug Del 2010;2:1-11.

38. Ali R, Nicola L, Chan-ju W. A new mechanism for azoreduction. $\mathrm{J}$ Molecular Bio 2010;1;1-16.

39. Klotz U, Maier K. Pharmacology and pharmacokinetics of 5aminosalicylic acid. Dig Dis and Sci 2005;32:46-50.

40. Chourasia MK, Jain SK. Polysaccharides for colon targeted drug delivery. Drug Deliv 2004;11:129-48.

41. Zhenig B, Jing G, Tong D. synthesis of aminosalicylglycine. Chinese Chem Lett 2005;16:88992.

42. Suneela SD, Mini K, Gaurav V. Synthesis, kinetic studies and pharmacological evaluation of mutual azo prodrug of 5aminosalicylic acid with L-tyrosine for colon specific delivery in inflammatory bowel disease. Euro J Med Chem 2007;42:885-90.

43. Roberta C, Sonia T, Alessia C, et al. L-Lysine pro-prodrug containing trans-ferulic acid for 5aminosalicylic acid colon delivery: synthesis, characterization and in vitro antioxidant activity evaluation. Chem Pharm Bull 2010;58:103-5. 
44. El-Kamel AH, Abdel-Aziz AA, Fatani AJ. Oral colon targeted delivery systems for treatment of inflammatory bowel diseases: synthesis, in vitro and in vivo assessment. Inter J Pharm 2008; 358:248-55.

45. Mahmut G, Hasan K, Murat $T$. Synthesis, spectral and thermal characterizations of some azo derivatives containing a 4acryloyloxy group. Dyes and Pigm 2007;72:101-8.

46. Cigdem A, Ismail EG, Mustafa O, et al. Synthesis, spectroscopic and molecular structure characterizations of some azo derivatives of 2hydroxyacetophenone. J Mol Stru 2009;932:43-54. 